\title{
PERSPECTIVE
}

\section{Baby Boomers and Beds: a Demographic Challenge for the Ages}

\author{
Zirui Song, $M D, P h D^{1,2}$ and Timothy G. Ferris, $M D, M P H^{2,3}$ \\ 'Department of Health Care Policy, Harvard Medical School, Boston, MA, USA; ${ }^{2}$ Department of Medicine, Massachusetts General Hospital, Boston, \\ MA, USA; ${ }^{3}$ Partners HealthCare, Boston, MA, USA.
}

The United States is facing a significant demographic transition, with about 10,000 baby boomers turning age 65 each day. At the same time, the nation is experiencing a similarly striking transition in hospital capacity, as the supply of hospital beds has declined in recent decades. The juxtaposition of population aging and hospital capacity portends a potentially widening divergence between supply and demand for hospital care. We provide a closer look at current hospital capacity and a rethinking of the future role of hospital beds in meeting the needs of an aging population.

J Gen Intern Med 33(3):367-9

DOI: $10.1007 / \mathrm{s} 11606-017-4257-\mathrm{x}$

(c) Society of General Internal Medicine 2017

$\mathrm{T}$ he United States is in the throes of a demographic transition. Approximately 10,000 baby boomers turn 65 years of age each day - a trend that will continue until 2030. Nearly the same number of seniors enter the Medicare program each day. According to the Congressional Budget Office, the share of the U.S. population age 65 and older is expected to increase from $15 \%$ today to $21 \%$ in 2046 , with aging contributing to growing health care spending. ${ }^{1}$

While the aging of the U.S. population has garnered increasing policy attention, the nation simultaneously faces a second transition - in hospital capacity. The supply of hospital beds in the U.S. has declined steadily in recent decades, owing in large part to hospital closures and restructuring of hospitals into post-acute facilities. The total number of hospital beds nationwide-following rapid growth from the 1800 s to the mid-1900s - has shrunk from over 1.6 million in 1960 to about 900,000 today. As a share of the population, the density of hospital beds has decreased from 2.8 per 1000 people in 2006 to 2.5 per 1000 in $2014 .^{2}$

The juxtaposition of population aging and shrinking number of hospital beds suggests a potentially growing divergence between bed demand and supply (Fig. 1). By 2060, the total number of U.S. seniors aged 65 and older will have doubled to 100 million - a statistic that is likely to be realized (rather than projected), as all of these future seniors have already been

Received May 30, 2017

Revised October 17, 2017

Accepted November 30, 2017

Published online December 22, 2017 born. While the trajectory of hospital bed supply is less certain, even under the conservative assumption that all of today's beds will remain available going forward, the chasm between presumed supply and demand threatens to widen. Under the assumption that hospital beds will continue to decline at the rate since 2000 , or faster, the gap between presumed supply and demand would expand quicker. Our figure is based on national data and does not examine underlying geographic variations in supply and demand, nor does it build in assumptions about hospitalization rates, length of stay, or changes in population growth or mortality rates. Related research has projected expected excess demand accounting for such factors. ${ }^{3}$

Should policymakers and the public be concerned? While at first glance the divergence between population aging and hospital beds may imply an impending shortage of beds, a closer look at current hospital capacity and rethinking of the future role of hospital beds may suggest that the U.S. delivery system is at a more nuanced crossroads - one that provides an opportunity for policymakers and potential innovations to reshape care delivery for an aging population.

\section{WHY WE SHOULD NOT BE WORRIED}

Several factors mitigate concerns of a looming bed shortage. On a typical day, over one third of hospital beds in the U.S. are unoccupied. In fact, not only are U.S. hospitals on average operating below their capacity, but excess capacity nationwide has actually increased. Over the last 10 years, the national bed occupancy rate has declined from $64 \%$ to $62 \%$, with rates of inpatient stays falling among both Medicare beneficiaries and commercially insured patients. ${ }^{2}$

In addition, the length of stay for U.S. hospitalizations decreased by $0.2 \%$ per year from 2003 to $2012 .{ }^{4}$ Consistent with this trend, technological advancements have enabled many specialties to transition care to outpatient settings. Heart attacks that once required weeks in the hospital can now be discharged approximately $24 \mathrm{~h}$ after a stent. Surgeries that once required a hospital stay can now be accomplished in ambulatory surgical centers. This substitution of hospital care for outpatient care is substantial among Medicare beneficiaries, whose inpatient discharges declined by $20 \%$ from 2006 to 2015, while their outpatient visits grew by $47 \%{ }^{4}$

The intensity of hospital use also varies substantially across the country. Nationally, this intensity is associated with the supply of hospital beds and physicians, but not necessarily 


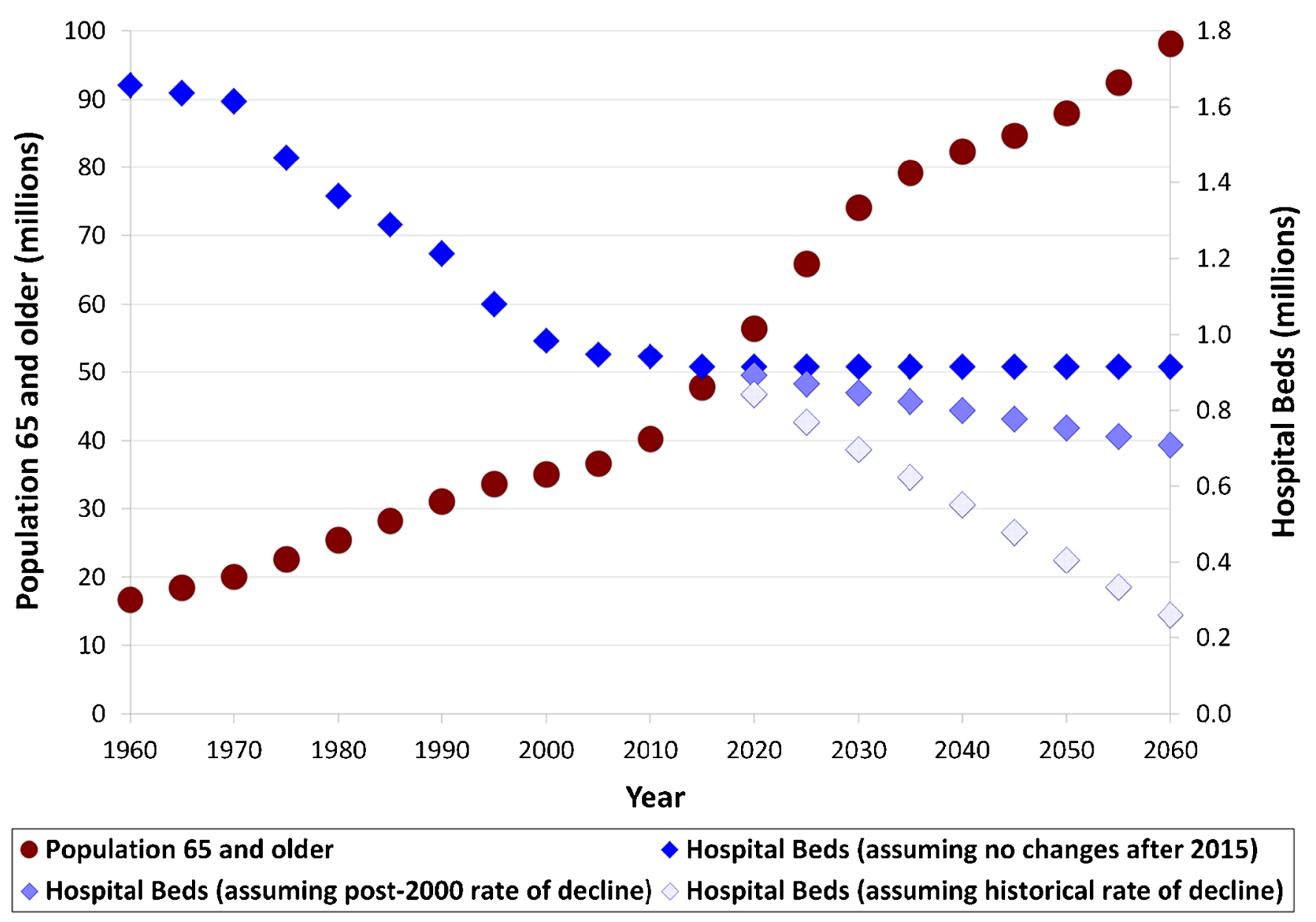

Figure 1 Population 65 years and older and hospital beds in the United States. Historical and projected population data are from the United States Census Bureau. Historical data on number of hospital beds are from the American Hospital Association annual surveys of hospitals. The number of hospital beds from 1960 and 1970 are from the article "The Nation's Hospitals: A Statistical Profile," Hospital Statistics. 1971.

Aug 1;45(Part 2),447. Projected number of hospital beds after 2015 are calculated using three assumptions: (1) no further decline in hospital beds after 2015, (2) linear change at the post-2000 rate of decline, and (3) linear change at the overall rate of decline since 1960.

with measurable differences in quality of care or survival, suggesting that the efficiency of hospital usage could be improved to create further capacity. ${ }^{5}$ Moreover, hospitals that close tend to have lower occupancy rates and poorer financial performance, and recent hospital closures have not been associated with changes in local hospitalization rates or mortality. ${ }^{6}$ Going forward, continued efforts to slow health care spending may continue to encourage the adoption of alternatives to hospital admission.

\section{WHY WE SHOULD BE WORRIED}

While excess capacity and more efficient hospital use may delay a national bed shortage in the near term, the demographic transition could prove overwhelming in the long run. Not only is the population aging, but it is doing so with an increasing burden of chronic disease that often requires acute intervention. Hospital beds will likely be needed for a substantial share of heart attacks, heart failure exacerbation, pneumonia, stroke, and other common acute conditions, especially in the elderly. While rates of heart disease and stroke among baby boomers are similar to those of the previous generation, and smoking rates have declined, ${ }^{2}$ a burgeoning prevalence of comorbidities such as diabetes and cancer-with associated detriments to kidney function or the immune system - may well compound the need for inpatient intervention. About $40 \%$ of today's baby-boomer population is obese, compared to $15 \%$ of the adult population in the 1970s, and baby boomers have a higher prevalence of diabetes and perhaps of cancer. ${ }^{2}$ Ultimately, not all hospital care can be transitioned to the outpatient setting, and lengths of stay cannot be compressed below a minimum reasonable time for treatment and monitoring prior to discharge or post-acute placement.

In addition, current efforts to enhance prevention and population health management under new payment systems with shared accountability between inpatient and outpatient care are still in relatively nascent stages nationwide. Bundled and global payments for populations that reward decreased hospital use, such as through fewer preventable admissions or readmissions, have yet to be broadly shown to reduce the need for hospital capacity. As population aging marches on, the 
pressure for successful payment and delivery system reform will intensify.

A growing elderly population presents hospitals with a further financial concern. Aggregate Medicare margins for hospitals have averaged about $-5 \%$ over the past 10 years and are expected to average about $-10 \%$ in 2017. (While Medicare payments have been below average costs, they have remained above the variable costs of treating Medicare patients; thus, hospitals with excess capacity can still obtain a marginal profit from caring for Medicare patients.) In contrast, average hospital all-payer profit margins nationwide have recently reached about 7\%, a 30-year high. ${ }^{2}$ In the long run, if an increasing share of hospitalized patients becomes Medicare beneficiaries, to what degree hospitals can remain financially sustainable with Medicare prices lower than commercial prices is unclear.

\section{RETHINKING HOSPITAL CAPACITY}

The collision between population aging and hospital capacity conjures up images of an unstoppable force (aging) against an immovable object (decreasing beds as a proportion of the population). Yet while aging is indeed unstoppable, hospital capacity may not be immovable. In today's health care landscape focused on cost control, building new hospital beds to keep pace with population aging is likely unrealistic. Continually squeezing lengths of stay also has its limits. If the need for hospitalizations does not slow, and outpatient substitution for inpatient care does not keep pace, the need for new and creative solutions will increase.

Repurposing current hospital capacity represents a potential option for responding to the needs of the aging population. While acute inpatient beds will remain important, the capital and human resources currently invested in fewer acute beds may be better directed towards creating community-based acute care capabilities, ranging from community hospitals, to semi-acute home hospitals, to newly imagined modes of care delivery such as mobile hospitals or clinics. Recent innovations including ambulatory surgical centers and urgent care centers may also be a part of the solution. While these newer forms of care delivery are increasingly prevalent, more evidence is needed to evaluate their ability to offset hospital capacity and their cost-effectiveness.

At the same time, reinvesting in and strengthening today's primary care capabilities to better anticipate or substitute for acute needs may serve a complementary role. For example, enrolling high-cost, high-need patients in intense care management programs, empowering allied health professionals and family members to be active members of the home care team, integrating mental and behavioral health into primary care, linking patients with health coaching and wellness programs, and building new community-based capacity through ideas such as the "ambulatory intensive care unit" are all possible ways that innovations in primary care could help prevent or alleviate future demand for hospital capacity. More research is needed on these types of strategies.

In the long run, the combination of such innovations in care delivery, further advances in information technology such as telehealth or e-consults, and pressure to control spending may lessen the reliance of the delivery system on today's paradigm of hospital care. For the broader U.S. economy, the need for these innovations and delivery system reforms to succeed is equally pressing. With a smaller share of the population working to finance the health care of a larger share of the population, and with Medicare's solvency under frequent threat, whether the hospital-centered delivery system can redefine itself to meet the needs of an aging population - especially as hospital beds become increasingly scarce — will be a crucial test in the years ahead.

Acknowledgements: Supported by a grant from the Office of the Director, National Institutes of Health (NIH Director's Early Independence Award, 1DP5OD024564-01, to Dr. Song). The authors are grateful for comments and suggestions from Jonathan Skinner, $\mathrm{PhD}$, Elliott Fisher, MD, MPH., Ellen Meara, PhD, and Samir Soneji, PhD, of the Dartmouth Institute for Health Policy and Clinical Practice on an earlier draft of this article.

Corresponding Author: Zirui Song, $M D, P h D$; Department of Health Care Policy Harvard Medical School, Boston, MA, USA (e-mail: song@hcp.med.harvard.edu).

\section{Compliance with Ethical Standards:}

Conflict of Interest: The authors declare that they do not have a conflict of interest.

\section{REFERENCES}

1. Congressional Budget Office. The 2016 Long-Term Budget Outlook. 2015. Available at: https://www.cbo.gov/publication/51580. Accessed 2 Nov 2017.

2. Medicare Payment Advisory Commission. Report to the Congress: Medicare Payment Policy. Washington, DC: Medicare Payment Advisory Commission; 2017.

3. Pallin DJ, Espinola JA, Camargo CA Jr. US population aging and demand for inpatient services. J Hosp Med. 2014;9(3):193-6.

4. Weiss AJ, Elixhauser A. Overview of Hospital Stays in the United States, 2012. HCUP Statistical Brief \# 180. 2014. Agency for Healthcare Research and Quality, Rockville, MD. Available at: https://www.hcup-us.ahrq.gov/ reports/statbriefs/sb180-Hospitalizations-United-States-2012.pdf. Accessed 2 Nov 2017

5. Fisher ES, Wennberg DE, Stukel TA, Gottlieb DJ. Variations in the longitudinal efficiency of academic medical centers. Health Aff (Millwood). 2004; Suppl Variation:VAR19-32.

6. Joynt KE, Chatterjee P, Orav EJ, Jha AK. Hospital closures had no measurable impact on local hospitalization rates or mortality rates, 200311. Health Aff (Millwood). 2015;34(5):765-72 